\title{
Analysis of Irrigation Systems Employing Comparative Performance Indicators: A Benchmark Study for National Irrigation and Communal Irrigation Systems in Cagayan River Basin
}

Jeoffrey Lloyd Reyes Bareng, Orlando Florendo Balderama and Lanie Alejandro Alejo

Isabela State University, Echague 3309, Isabela, Philippines

\begin{abstract}
Comparative performance analysis of four irrigation schemes within Cagayan River Basin was assessed using comparative performance indicators between the years 2008 and 2012. The objectives were to establish benchmarks for both productivity and performance of irrigation schemes along the valley and to inquire whether small schemes function better than large schemes. The performance evaluation study of the systems composed of three general performance indicators, based on three domains-(1) system operation performance; (2) agricultural productivity and economics; (3) financial performance. Each indicator was assessed based on the prescribed descriptors used by the International Water Management Institute (IWMI) and Food and Agriculture Organization (FAO). Analysis showed an overall system performance efficiency of 59\%, 55\%, 47\% and 36\% for Magat River Integrated Irrigation System (MARIIS), Lucban, Garab and Divisoria Communal Irrigation Systems (CIS), respectively. In terms of annual productivity performance, Lucban CIS dominates the three other systems with $0.35 \mathrm{~kg} / \mathrm{m}^{3}$, which was classified as moderately performing system, while the rest were classified with low productivity index. Financial sustainability of the systems were extremely poor with cost recovery ratio of $0,0.33,0.41$ and 0.49 for Divisoria, Garab, Lucban and MARIIS, respectively, which were exceptionally below the standard value of at least one. Also, analysis of the indicators revealed that on average, large schemes performed similarly to small-scale schemes, but small schemes were more variable, particularly in input-use efficiency. The benchmarking study will provide strategic information to policy makers of agricultural and irrigation agencies on the existing weaknesses of irrigation systems in the country and determine in a more quantifiable terms levels of potential improvement and intervention targets.
\end{abstract}

Key words: Communal and national irrigation systems, performance benchmarking, small and large reservoir schemes.

\section{Introduction}

Benchmarking is already widely accepted and advocated by several organizations worldwide, such as, International Program for Technology and Research in Irrigation and Drainage (IPTRID), International Water Management Institute (IWMI), International Commission on Irrigation and Drainage (ICID), World Bank (WB) and Food and Agriculture Organization of the United Nations (FAO), because it is a very powerful management tool for analyzing and

Corresponding author: Jeoffrey Lloyd Reyes Bareng, assistant professor, research fields: climate change and water resources, hydrologic modeling and simulation, irrigation and water management, soil and water conservation. improving the performance of water resources projects [1]. In the case of Magat River Integrated Irrigation System (MARIIS) and Communal Irrigation Systems (CIS), there has been an urgent issue to be addressed to improve the performance of these systems. Initial benchmarking on the current situation of the system using standard domains and indicators were considered to produce strategic information for effective short and long term measures and plan to manage water resources more efficiently, sustainably and productively, which enables managers to compare the processes with the best practices and adopt suitable ones which would eventually improve the efficiency of the system and will result in savings in 

for National Irrigation and Communal Irrigation Systems in Cagayan River Basin

water usage thereby increasing the systems coverage [2].

For this study, two irrigation domains were covered as follows:

(a) Service delivery: this domain includes two areas of service provision: (1) the adequacy with which the organization manages the operation of the irrigation delivery system to satisfy the water required and (2) the efficiency with which the organization uses resources to provide this service (financial performance);

(b) Productive efficiency: measures the efficiency with which irrigated agriculture uses water resources in the production of crops and fibre.

Case studies in the Philippines and other Asian countries reveal that utmost benefits from irrigation development are not fully realized for a variety of reasons which leads to sub-optimal irrigation performance, as such, decrease in irrigated areas, cropping intensity, crop yield and among others [3]. Also, a number of studies conducted to assess the performance of several irrigation systems revealed that these systems performed below the expectations [4-9].

Lack of rainfall in the dry season and dry spells in the rainy season due to changing climate, however, are among the major constraints to rice production, and water productivity in paddy fields is perceived to be low. Improving the performance of irrigation scheme at MARIIS and CIS is an obvious issue for agricultural development. Irrigation efficiency, which is an indicator of effective water resources management, varies from area to area. A particular concern is water shortage within irrigation scheme command areas, particularly in the dry season or in dry spells during the rainy season [10].

In the case of MARIIS, another major concern is growing presence of fishponds constructed along the main and secondary canals in the upstream reach. Based on the result of a study, there were approximately 300 ha of fishponds already established along the south high canal area alone, whose water requirements are being drawn freely without any regulation. Further, the study revealed that about 6.73 $\mathrm{m}^{3} / \mathrm{s}$ or equivalent to $28 \%$ of the $24 \mathrm{~m}^{3} / \mathrm{s}$ irrigation diversion requirements (IDR) is lost due to excessive use of water by fishponds operators. On the other hand, Small Water Impounding Project (SWIP) is perceived to be performing poorly, which is the way below of what was expected based on the latest system inventory [11].

Therefore, improvement of efficiency can improve equity in water distribution and minimize the gap between potential crop water requirements and actual water use. In consequence, it will lead to the determination of the effectiveness of water use and the improvement of the livelihood of people [12]. Farmers can use lesser water or lower input investment while obtaining higher production and remaining more water in the sources, which can maintain the ecological cycle and environment of river basin.

Furthermore, in many irrigation projects, there is no baseline information (physical, institutional and management) regarding the levels of service to water users (farmers and fisherfolks) and the factors which affect those services. Establishing baseline information regarding the levels of service, determining standards and then determining how to meet them could be crucial for improving the design, upgrading and management of irrigation and drainage projects.

Hence, the objective of this research was to assess the performance of small and large reservoir irrigation schemes in Cagayan River Basin. Specifically, the paper aimed to determine and establish benchmarks for both productivity and performance using standard indicators - irrigation efficiency, adequacy of water supply, productivity of land and water resources and financial viability of the schemes.

\section{Description of the Study Sites}

The four systems (namely, small systems Divisoria, Garab, Lucban SWIP and large system NIA-MARIIS, 

for National Irrigation and Communal Irrigation Systems in Cagayan River Basin

respectively) were all strategically situated within the Cagayan River Basin. The Cagayan River Basin lies in the Northeastern tip of the Philippines as shown in Fig. 1. The Cagayan River flows through the four mainland provinces and is the largest river system in the country. It is located between $15^{\circ} 52^{\prime} \mathrm{N}-18^{\circ} 23^{\prime} \mathrm{N}$ latitudes and $120^{\circ} 51^{\prime}$ E- $122^{\circ} 19^{\prime}$ E longitudes. Based on the data from Ref. [13], the potential irrigable area in Cagayan Valley is about 472,640 ha, of which only $46.32 \%$ was irrigated as of the year 2000 . That leaves more than 200,000 ha yet to be provided with irrigation facilities. These potential irrigable areas include rainfed areas and areas presently planted to corn and other agricultural commodities. While areas suitable for rice may have been underutilized, there are also marginal rice lands that are actually more suitable for other crops [14].

\subsection{MARIIS at a Glance}

The MARIIS has four distinct divisions I, II, III and IV as shown in Fig. 2. Pilot locations were considered as representation of typical canal system with appropriate

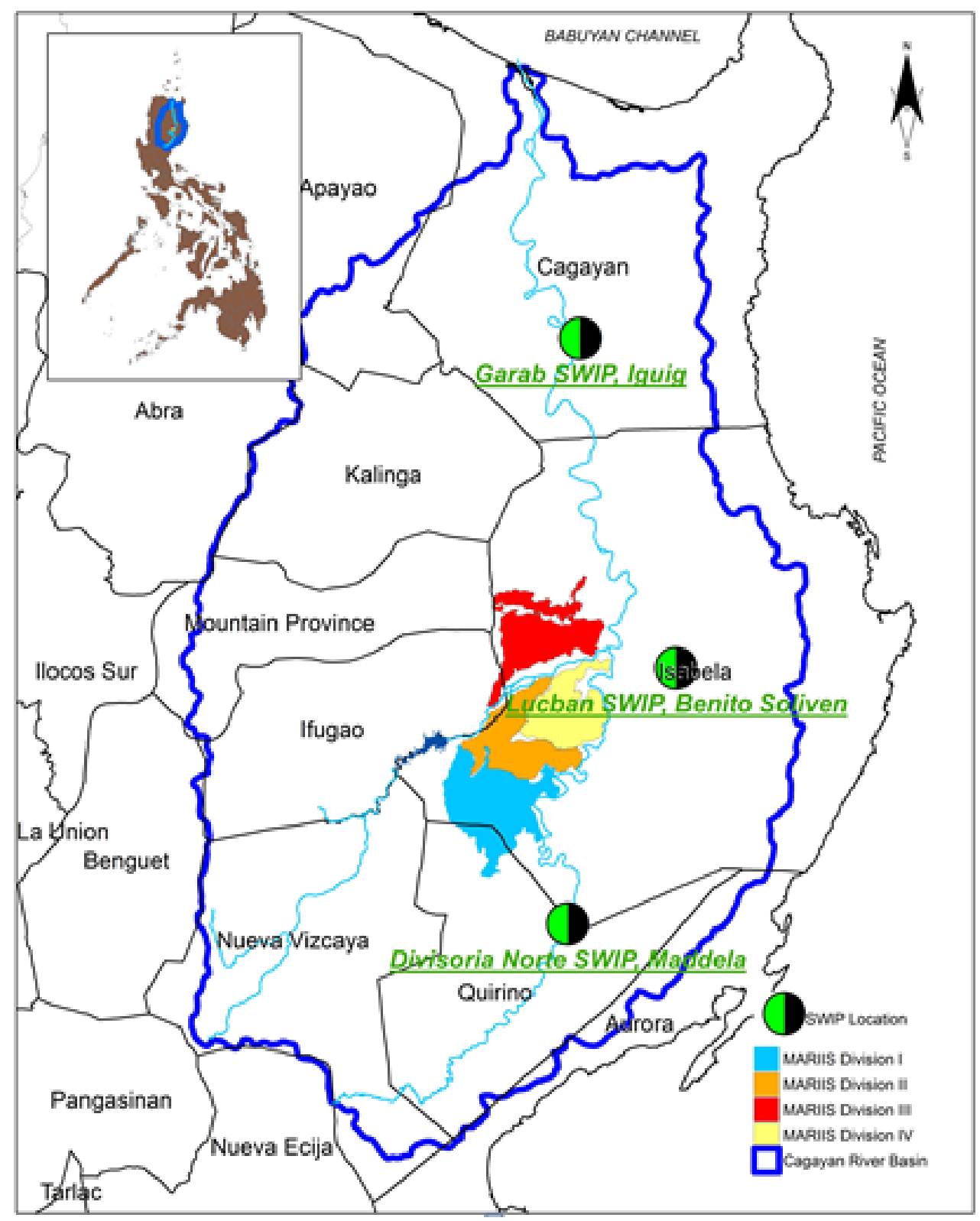

Fig. 1 Distribution of selected study sites. 

for National Irrigation and Communal Irrigation Systems in Cagayan River Basin

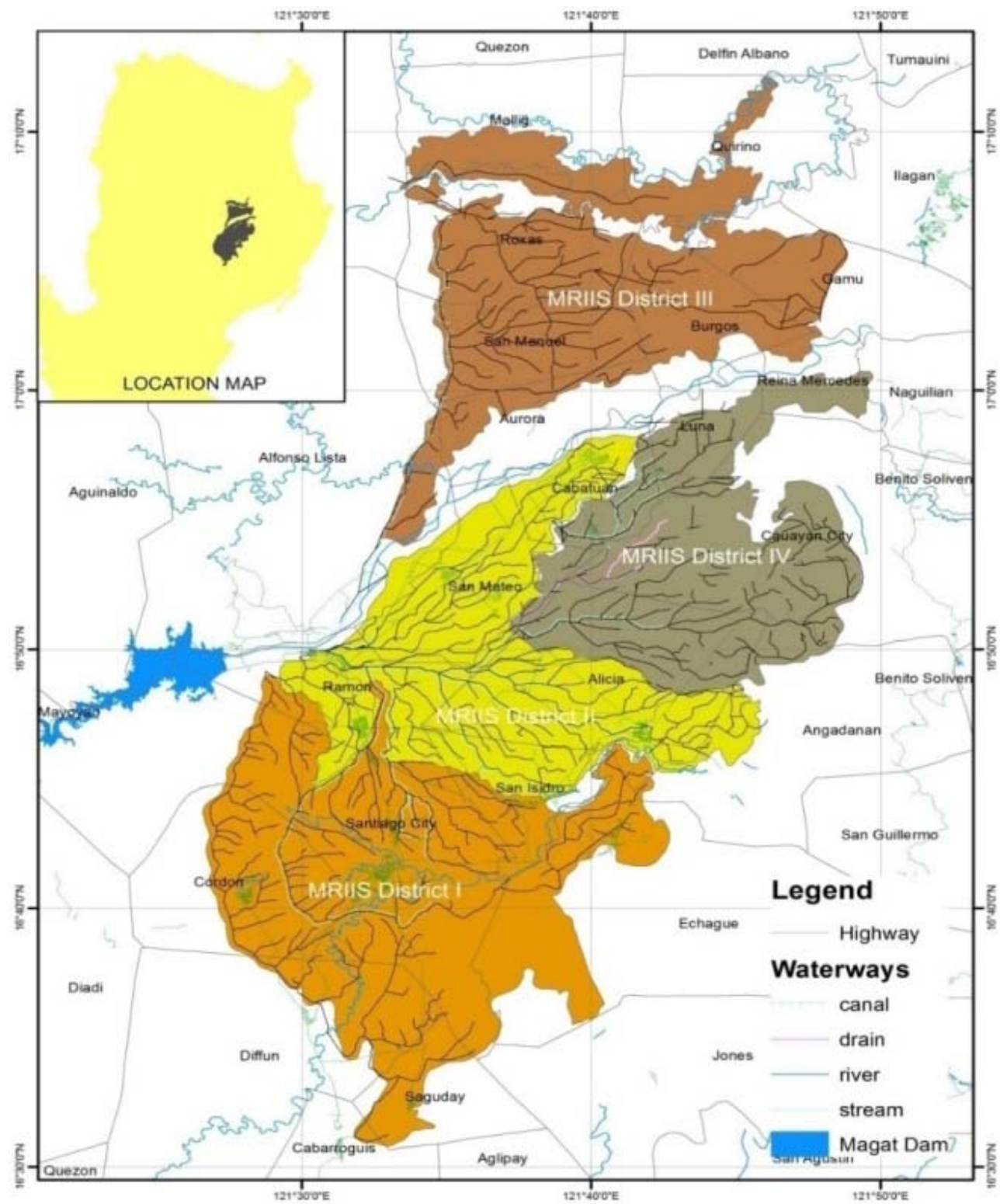

Fig. 2 MARIIS service area indicating the distinct divisions.

size of command areas, considering accessibility and availability of relevant information. Study period considered in the benchmarking analysis is five years covering two cropping season from 2008 to 2012.

The Magat River multi-purpose system was built in 1975 to provide dependable water supply for irrigation and power generation. The project area includes the service area of the two existing irrigation systems, namely MARIIS and Siffu Irrigation System (SIFRIS), and these together with all the appurtenant facilities and structures brought the present firmed-up service area to 84,795 ha. On the other hand, the Magat hydroelectric power plant constructed below the Magat dam has an initial installed capacity of 360 megawatts with a provision to increase its capacity to 540 megawatts. With the government's program to privatize the generating assets of the National Power Corporation (NPC) as mandated by the electric power industry reform act (EPIRA) law, the ownership of the power plant was transferred from the NPC to SN-ABOITIZ effective on April 25, 2007.

MARIIS 5-year (2008-2012) average service area is $78,496.20$ ha, which composes of four distinct divisions, namely, division I (Santiago City cluster), 

for National Irrigation and Communal Irrigation Systems in Cagayan River Basin

district II (San Mateo cluster), district III (Roxas cluster) and district IV (Cauayan cluster) with corresponding service area distribution $25.00 \%$, $28.98 \%, 23.28 \%$ and $22.70 \%$, respectively, as shown in Fig. 3.

\subsection{Present Status of Irrigation Utilization}

Besides of various measures taken so far to equalize the amount of targeted vs. actual cultivated area, there is still a gap between the two values as depicted in Fig. 4. A 5-year target and actual utilization within MARIIS from 2008 to 2012 is exhibited in Fig. 4.

Fig. 5 shows that there is an annual gradual improvement in terms of area served by the system from $2008-2012$ by $3.34 \%$, however, there is still under utilization of almost $2 \%$. While in terms of 5-year season-wise representation of actual area irrigated as depicted in Fig. 5, remarkable linear increase of irrigated hectarage both during the dry and wet seasons were attained by $3.79 \%$ and $2.91 \%$, respectively. Peak increase is noted for both seasons during the year 2011 with a slight decrease in irrigated area for the dry and wet seasons.

\subsection{The Case of Small Water Impounding Projects in} Cagayan River Basin

In Philippines, rainwater harvesting project (i.e., with its institutional title SWIP) is a structure constructed across a narrow depression or valley to hold back water and develop a reservoir that will store rainfall and run-off during the rainy season for immediate or future use.

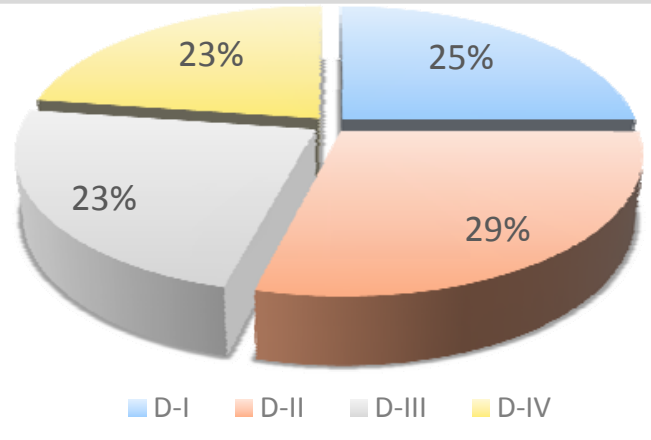

Fig. 3 MARIIS actual service area distribution.

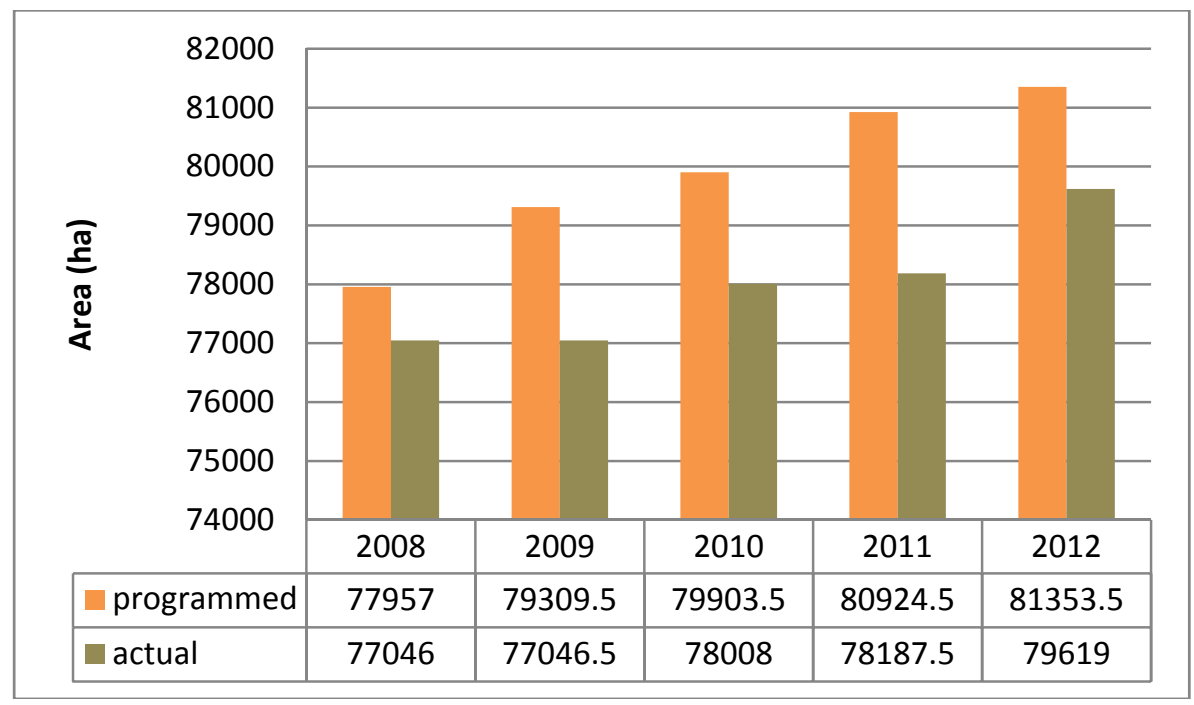

Fig. 4 MARIIS programmed vs. actual irrigated area. 

for National Irrigation and Communal Irrigation Systems in Cagayan River Basin

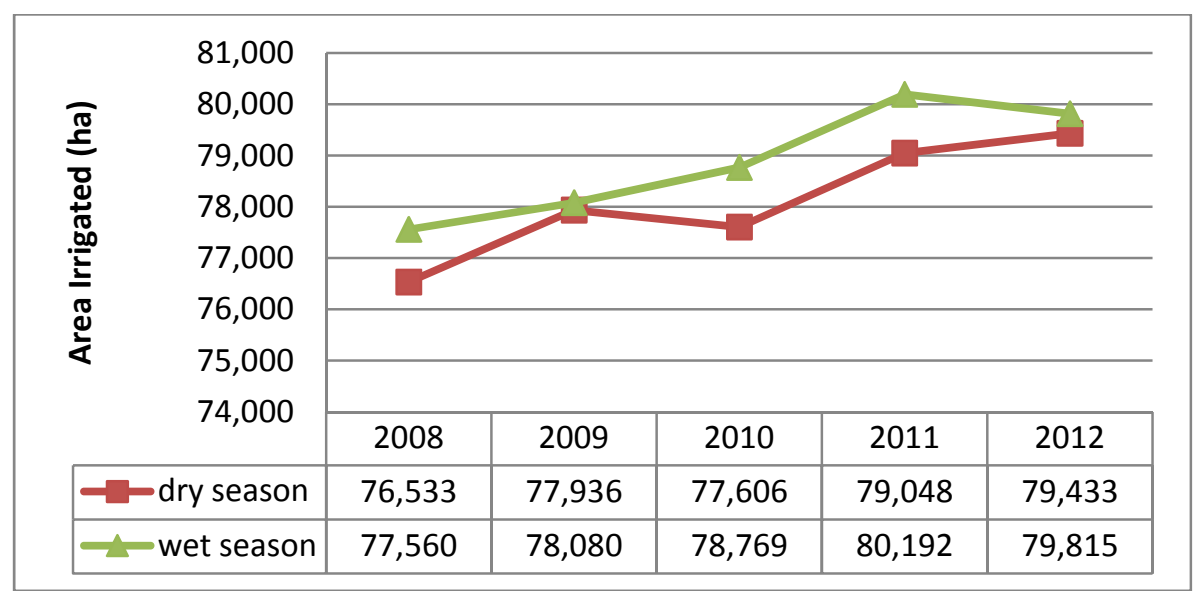

Fig. 5 MARIIS progress in irrigated hectarage.

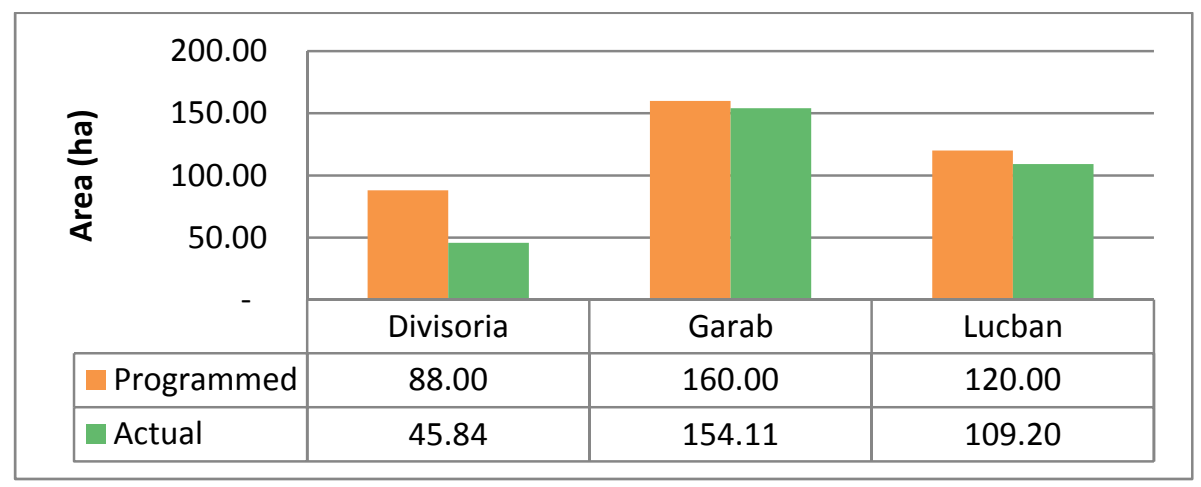

Fig. 6 SWIPs study area showing the programmed vs. actual area irrigated.

In December 2011, the Bureau of Soils and Water Management estimated that there are 103 units of SWIP in the Cagayan Valley region with a total service area of 6,353 ha and 4,929 farmer beneficiaries. However, there still is a gap between the programmed and actual irrigated area at selected sites, particularly at Divisoria SWIP with only 50\% served by the system as depicted in Fig. 6 .

\section{Methods}

\subsection{Data Collection}

General methods and activities were as follows: (1) review of documents and site validations; (2) key informant interviews, focus group discussions and household survey; (3) focus group discussions; (4) on-field measurements/inspections/observations.

\subsection{Review of Documents and Site Validation}

In the case of SWIPs, thorough study of previous reports, inventory, manuals and designs of SWIP in Cagayan Valley was conducted. Three SWIP pilot sites in Cagayan Valley were selected for detailed study. Initially, SWIP at Divisoria in Maddela Quirino, Garab in Ilagan Isabela and Iguig in Cagayan were selected and subjected to validation visit. The selection was made based on the earlier studies and recommendations by the Regional Agricultural Engineering Group (RAEG) of the Department of Agriculture. The identified SWIPs are considered ideal sites and representative sites of SWIPs in the region.

Existing and field data were collected related to water resources within the selected irrigation systems. Water discharges in various sections of main canals, cropped area for the two seasons and cropping intensity and paddy production.

\subsection{Benchmarking Irrigation Systems Performance}

The performance indicators used for this study was 

for National Irrigation and Communal Irrigation Systems in Cagayan River Basin

adopted from the internationally recognized standard indicators set by IWMI, FAO, IPTRID and ICID. Such irrigation domains covered in the study are as follows:

(a) Service delivery: this domain includes two areas of service provision: (1) the adequacy with which the organization manages the operation of the irrigation delivery system to satisfy the water required and (2) the efficiency with which the organization uses resources to provide this service (financial performance);

(b) Productive efficiency: measures the efficiency with which irrigated agriculture uses water resources in the production of crops and fibre.

Table 1 shows the specific domains for benchmarking with their corresponding specific performance indicators selected.

\section{Results}

The results of the irrigation performance indicators analyses based on three domains-(1) system operation performance, (2) agricultural productivity and economics and (3) financial performance, respectively.

\subsection{System Operation Performance}

The provision of water for irrigation and electric generation are the purposes of the Magat dam reservoir system. However, the system's first priority is the provision of dependable irrigation water supply to farm lands. Though, distribution of such water resource is influenced by numerous factors, such as, physical, climatic, economic and other related factors which eventually affect the delivery performance of the system. Measurements on the system operation performance were based on specific indicators, such as, (a) delivery of the system, (b) annual irrigation water supply and (c) annual relative water supply. The results of system delivery efficiency, annual irrigation supply and relative water supply for MARIIS and the three SWIPs selected sites were presented in Fig. 7.

\subsubsection{System Irrigation Efficiency}

The system delivery efficiency was significantly different for the whole MARIIS, Lucban, Garab, and Divisoria schemes. The MARIIS shows the highest efficiency value of $59 \%$, but Lucban SWIP is statistically comparable with efficiency value of $55 \%$, while the two other SWIPs, namely, Garab and

Table 1 Specific domains used for benchmarking.

\begin{tabular}{ll}
\hline Domain & Performance indicator \\
\hline \multirow{2}{*}{ Service/system operation performance } & System irrigation efficiency \\
& $\begin{array}{l}\text { Annual irrigation water delivery per unit irrigated area }\left(\mathrm{m}^{3} / \mathrm{ha}\right) \\
\text { Annual relative water supply }\end{array}$ \\
\hline Productive efficiency & Output per unit irrigated area $(\mathrm{Peso} / \mathrm{ha})$ \\
\hline \multirow{2}{*}{ Financial performance } & Output per unit irrigation supply $\left(\mathrm{Peso} / \mathrm{m}^{3}\right)$ \\
& Cost recovery ratio \\
& $\begin{array}{l}\text { Revenue collection performance } \\
\text { Cost recovery ratio }\end{array}$ \\
\hline
\end{tabular}

\section{DIVISORIA GARAB LUCBAN MARIIS}

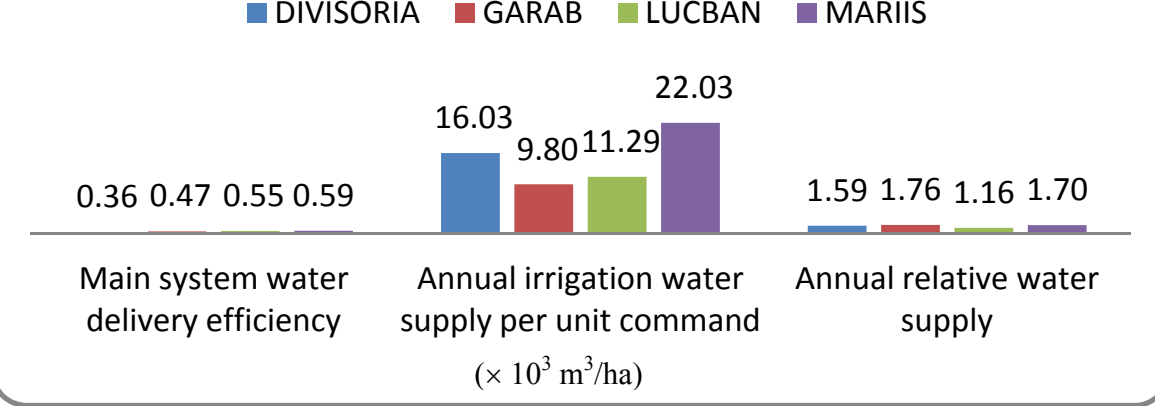

Fig. 7 System-wise operation performance indicators. 

for National Irrigation and Communal Irrigation Systems in Cagayan River Basin

Divisoria were slightly lower than the previous systems with efficiency values of $47 \%$ and $36 \%$, respectively. Although MARIIS and Lucban schemes are significantly higher compared to Garab and Divisoria SWIPs, these systems are quiet lower than irrigation efficiency of other irrigation schemes worldwide. Bandara [15] estimated that the irrigation efficiency of major irrigation system in Sri Lanka reach as high as 71\%. Also, surface irrigation efficiency ranges between $50 \%$ and $60 \%$ in Israel, Japan and Taiwan [16].

4.1.2 Annual Irrigation Water Delivery per Unit Irrigated Area $\left(\mathrm{m}^{3} / \mathrm{ha}\right)$

This indicator is a measure on the total quantity of water supplied for irrigation throughout the year compared to the total area irrigated for the whole system selected. Although annual irrigation water supply per unit irrigated area depends on several factors, such as, water availability, cropping pattern climate, soil type, systems condition and management, the four systems average performance in terms of annual irrigation water delivery per unit irrigated area measured was significantly different as depicted in Fig. 7, where MARIIS registered the highest amount of $22,029.43 \mathrm{~m}^{3} / \mathrm{ha}$, tailed by Divisoria and Lucban SWIPs with comparable amount of $16,026.37 \mathrm{~m}^{3} /$ ha and $11,289.10 \mathrm{~m}^{3} / \mathrm{ha}$, respectively, and Garab registered the least amount of $9,795.96 \mathrm{~m}^{3} / \mathrm{ha}$.

\subsubsection{Annual Relative Water Supply}

The relative water supply is a suitable indicator to show whether crop water requirements of an area were sufficiently provided. Annual relative water supply for all the systems considered was comparable as reflected in Fig. 7. However, values are relatively lower as compared to the schemes of other systems in the world with only 1.70, 1.16, 1.76 and 1.59 for MARIIS, Lucban, Garab and Lucban SWIP, respectively, while that of the 18 irrigation systems located in 11 countries in the Asian region vary between 0.8 and 4.0, with more a half of these systems have annual relative water supply of greater than $2[17$, 18]. These low values within the selected systems indicate that adequacy of supplied irrigation water is adversely affected by the low system delivery efficiencies.

\subsection{Agricultural Productivity and Economics}

\subsubsection{Output per Unit Irrigation Supply $\left(\mathrm{kg} / \mathrm{m}^{3}\right)$}

This water productivity indicator is a measure of the optimal utilization of water in relation to the total agricultural production served by the system. The comparison of data on output per unit irrigation supplied is shown in Fig. 8. Although differences are not pronounced between Divisoria, Garab and MARIIS systems, however, Lucban SWIP has significant output value of $0.35 \mathrm{~kg} / \mathrm{m}^{3}$. According to the water productivity categorization levels [19], the systems performance ranks as low if less than 0.35 $\mathrm{kg} / \mathrm{m}^{3}$, moderate if between $0.3 \mathrm{~kg} / \mathrm{m}^{3}$ to $0.4 \mathrm{~kg} / \mathrm{m}^{3}$ and high if greater than $0.4 \mathrm{~kg} / \mathrm{m}^{3}$. Accordingly, the

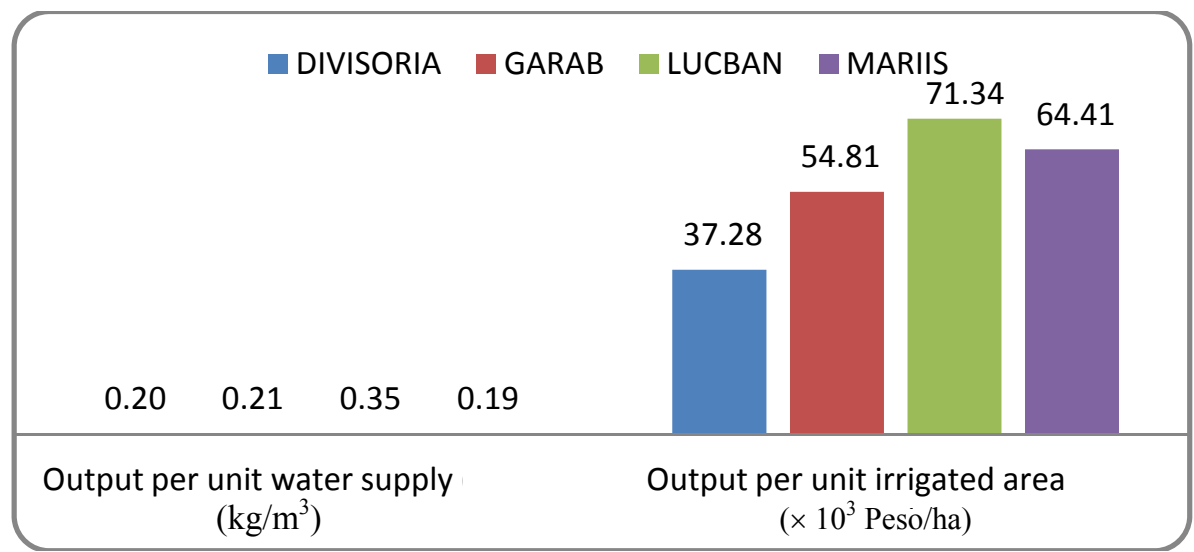

Fig. 8 System-wise agricultural productivity performance indicators. 


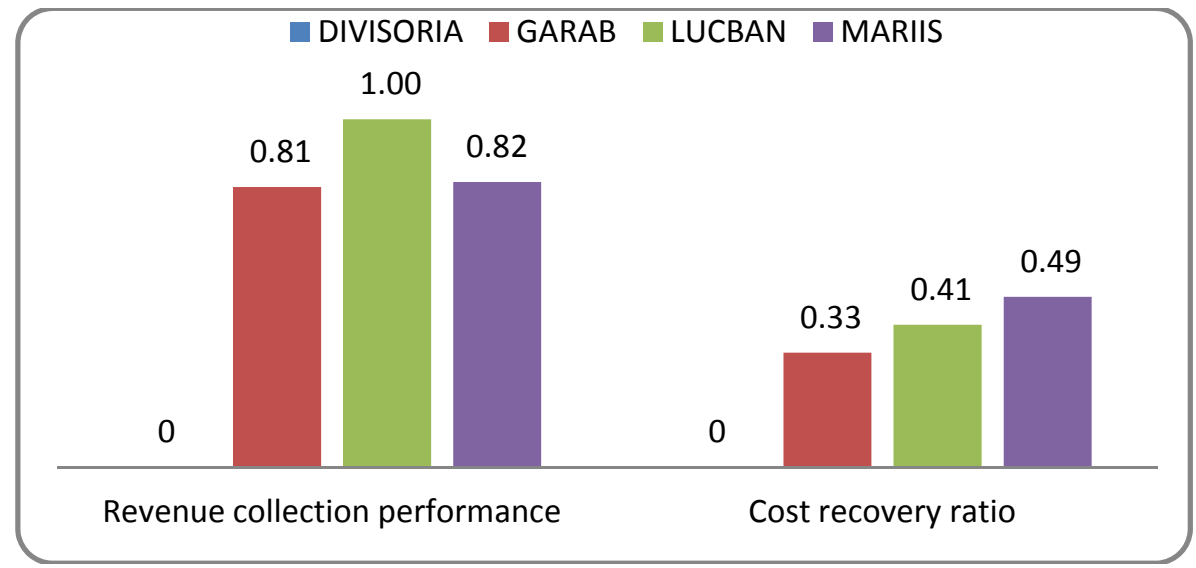

Fig. 9 System-wise financial performance indicators.

productivity classification of Lucban SWIP can be considered as moderate; while the rest Divisoria, Garab and even MARIIS system are categorized under low productivity index. Subsequently, besides Lucban was considered to be the highest among the four irrigation systems under study, its grain productivity was still lower compared to global grain average ranging from $0.76 \mathrm{~kg} / \mathrm{m}^{3}$ to $1.23 \mathrm{~kg} / \mathrm{m}^{3}$ [20].

\subsubsection{Output per Unit Irrigated Area (Peso/ha)}

This indicator quantifies the performance of the system in terms of production output in a given unit irrigated area in Peso/ha basis. This indicator is very much important, since water is the only factor on which the service provider has full control linked with the adoption of improved/latest technology, as the population grows while land holding per capita goes on reducing. For the four systems, land productivity performance is reflected in Fig. 8, where Lucban yielded the highest output with comparable output value of MARIIS of 71,336.22 Peso/ha and 64,412.15 Peso/ha, respectively. Generally, results indicate a highly significant scope to increase land and water productivity for the four irrigation systems as indicated by the variable and low productivity performance.

\subsection{Financial Performance}

4.3.1 Revenue $/ \mathrm{m}^{3}$ of Irrigation Water Supply $\left(\mathrm{Peso} / \mathrm{m}^{3}\right)$

Revenue $/ \mathrm{m}^{3}$ of irrigation water supply is the ratio of the total revenue and gross volume of water supplied for irrigation during the irrigation year. This indicator is very important measure, as every drop of water needs to be used efficiently and economically. In the case of Lucban, irrigation fee collection performance is $100 \%$; while $81 \%$ and $82 \%$ collection efficiency were attained at Garab and MARIIS, respectively, as shown in Fig. 9. However, there was no collection effort made at Divisoria SWIP.

\subsubsection{Cost Recovery Ratio}

Cost recovery ratio is the ratio of recovery of water charges to the cost of providing the service. It is imperative to consider this indicator for the design of water rates and recovery mechanism for the sustainable operation of the system. On the basis of sustainability, the theoretical cost recovery ratio for any system should be at least equal to one. However, the four systems have poor cost recovery ratio of 0 , 0.33, 0.41 and 0.49 for Divisoria, Garab, Lucban and MARIIS, respectively, as presented in Fig. 9, where it is half-way below the theoretical value for system sustainability [21].

\section{Conclusions}

This study focused on assessment of the performance of small (Lucban, Garab and Divisoria SWIPs) and large (NIA-MARIIS) reservoir irrigation schemes. The results showed relatively low performance of the four systems being assessed as manifested by irrigation efficiency of $59 \%, 55 \%, 47 \%$ 

for National Irrigation and Communal Irrigation Systems in Cagayan River Basin

and 46\% for MARIIS, Lucban, Garab, and Divisoria, respectively. Thereby, improving the systems delivery and distribution efficiency could eventually support the targeted service area of each system as being indicated by the considerable amount annual relative water supply of 1.70, 1.16, 1.76 and 1.59 for MARIIS, Lucban, Garab and Lucban SWIP, respectively, which is quite near the world average relative irrigation water supply of 2.0.

In terms of water and land productivity of the four scheme, it was $0.20,0.21,0.35,0.19 \mathrm{~kg} / \mathrm{m}^{3}$ and 37,276.01, 54,813.40, 71,336.22, 64,412.15 Peso/ha, respectively, for Divisoria, Garab, Lucban and MARIIS schemes. Besides, the low productivity of the systems, except for Lucban, were classified as moderate performing, but quit low compared to global average productivity index ranging from 0.76 to 1.23 $\mathrm{kg} / \mathrm{m}^{3}$.

Financial sustainability of the systems were extremely poor as indicated by the low cost recovery ratio of $0,0.33,0.41$ and 0.49 for Divisoria, Garab, Lucban and MARIIS schemes, respectively, which were exceptionally below the standard value of at least one. Thus, to insure sustainable operation of the systems, wise mechanism recovery design should be implemented for each system being considered.

The study confirmed that a national and communal irrigation schemes within the Cagayan River Basin were on the average performed similarly; however, both schemes performed quit below the world standard in terms of irrigation efficiency, land and water productivity levels and financial viability of the schemes. With the result of the analysis, it is therefore necessary to consider an over-all system improvement in terms of the three basic domains used, as such, (1) system operation performance, which includes but not limited to improvement on conveyance and distribution systems; (2) agricultural productivity and economics, which embraces superior production management practices, like adoption of high yielding varieties, appropriate fertilization technologies, water management scheme, etc.; (3) financial performance, which should consider wise mechanism recovery design and implementation.

\section{Acknowledgments}

The authors extend their acknowledgement to the Department of Agriculture, Region 2 and SN-ABOITIZ, Inc., for providing financial and technical support for the completion of this work. Also thanks to the NIA-MARIIS for generously providing valuable importation which enables the authors to conclude the project.

\section{References}

[1] Malano, H., and Burton, M. 2001. Guidelines for Benchmarking Performance in the Irrigation and Drainage Sector. International Programme for Technology and Research in Irrigation and Drainage (IPTRID), FAO.

[2] Malano, H. M., Molden, D. J., Bos, M. G., and Vlotman, W. F. 2004. Benchmarking of Irrigation and Drainage Projects. International Commission on Irrigation and Drainage (ICID) Task Force Report, New Delhi, India.

[3] Labiano, B. S. 2014. Agricultural Water Management Systems in the Philippines: Current Status and Policy Directions. National Irrigation Adminstration, Quezon City, Philippines.

[4] Ferguson, C. 1987. "Returns to Irrigation Intensification in Philippine Gravity Systems." Ph.D. thesis, Cornell University, Ithaca, New York.

[5] David, W. P. 1986. "Policy Issues on Irrigation." In Agenda for Action for the Philippine Rural Sector. Laguna, Philippines: University of the Philippines Los Baños, 28-56.

[6] David, W. P. 2000. "Constraints, Opportunities and Options in Irrigation Development.” Discussion Paper No. 2000-39, Philippine Institute of Development Studies (PIDS), National Economic Development Authority, Manila. Accessed May 17, 2000. http://core.ac.uk/download/pdf/7105189.pdf.

[7] David, W. P. 2003. Averting the Water Crisis in Agriculture: Policy and Program Framework for Irrigation Development in the Philippines. Quezon City, Philippines: University of the Philippines Press, 168.

[8] David, W. P. 2008. "Irrigation." In Modernizing Philippine Agriculture and Fisheries: The AFMA Implementation Experience, edited by Dy-Rolando, T., Gonzales, L. A., Bonifacio, M. F., David, W. P., De Vera III, J. P. E., Lantican, F. A., Llanto, G. M., Martinez, L. 


\section{Analysis of Irrigation Systems Employing Comparative Performance Indicators: A Benchmark Study for National Irrigation and Communal Irrigation Systems in Cagayan River Basin}

O., and Tan, E. E. Manila: University of Asia and the Pacific, 85-128.

[9] David, W. P. 2009. "Impact of AFMA on Irrigation and Irrigated Agriculture." Philippine Agricultural Scientist 91 (3): 315-28.

[10] Sinuany-Stern, Z., Mehrez, A., and Hadad, Y. 2000. “An AHP/DEA Methodology for Ranking Decision Making Units." International Transactions in Operational Research 7 (2): 109-24.

[11] Philippines Bureau of Soils and Water Management (BSWM). 2011. Report on Completed and Operational Small-Scale Irrigation System.

[12] Molden, D. J., and Gates, T. K. 1990. "Performance Measures for Evaluation of Irrigation Water Delivery Systems." Journal of Irrigation and Drainage Engineering 116 (6): 804-23.

[13] The National Irrigation Administration (NIA). 2011. "Status of Irrigation Development." Accessed December 31, 2014. http://www.nia.gov.ph./updates/statusof irrigationdevelopment.pdf.

[14] National Economic Development Authority (NEDA). 2011. "Regional Development Plan, Cagayan Valley, Philippines." Accessed October 28, 2014. http:/www.neda.gov.ph/wp-content/uploads/2013/10/Reg II RDP 20111-2016.pdf.

[15] Bandara, K. M. P. S. 2003. "Monitoring Irrigation Performance in Sri Lanka with High-Frequency
Crystallite Measurements during the Dry Season." Agricultural Water Management 58: 159-70.

[16] Perry, C., Steduto, P., Allen, R. G., and Burt, C. M. 2009. "Increasing Productivity in Irrigated Agriculture: Agronomic Constraints and Hydrological Realities." Agricultural Water Management 96 (11): 1517-24.

[17] Molden, D., Frenken, K., Barker, R., De Fraiture, C., Mati, B., Svendsen, M., Sadoff, C., and Finlayson, C. M. 2009. "Trends in Water and Agricultural Development." In Water for Food, Water for Life: A Comprehensive Assessment of Water Management in Agriculture. London: Earthscan, 57-89.

[18] Karatas, B. S., Akkuzu, E., Unal, H. B., Asik, S., and Avci, M. 2009. "Using Satellite Remote Sensing to Assess Irrigation Performance in Water User Associations in the Lower Gediz Basin, Turkey." Agricultural Water Management 96 (6): 982-90.

[19] Cai, X. L., and Sharma, B. R. 2010. "Integrating Remote Sensing, Census and Weather Data for an Assessment of Rice Yield, Water Consumption and Water Productivity in the Indo-Gangetic River Basin." Agricultural Water Management 97 (2): 309-16.

[20] Falkenmark, M., and Rockström, J. 2004. Balancing Water for Humans and Nature: The New Approach in Ecohydrology. London, UK: Earthscan Publications Ltd..

[21] IWMI, WorldFish, ILRI and NBI. 2009. The Nile Basin Focal Project. CPWF Project Number 59 Report. 